\title{
Effect of silver nano particle, ferrous sulfate and hydrogen peroxide on photodgradtion of Tornasole RPe and Alizarin yellow G
}

\author{
Sawsan Mohamed Abu El Hassan Mosa ${ }^{1,2}$ \\ ${ }^{1}$ Department Analytical and Inorganic Chemistry, Suez Canal University, Faculty of Education el Arish, Egypt \\ ${ }^{2}$ Faculty of Art and Science, Shaqra University, Sajir, K.S.A.
}

\section{Email address:}

sawsan22005@hotmail.com

\section{To cite this article:}

Sawsan Mohamed Abu El Hassan Mosa. Effect of Silver Nano Particle, Ferrous Sulfate and Hydrogen Peroxide on Photodgradtion of Tornasole RPe and Alizarin Yellow G. Science Journal of Analytical Chemistry. Vol. 3, No. 1, 2015, pp. 1-5.

doi: 10.11648/j.sjac.20150301.11

\begin{abstract}
Many industries such as paper, food, cosmetics, textiles etc. use dyes in order to color their products. The presence of these dyes in water even at very low concentration is highly visible and undesirable. Color is the first contaminant to be recognized. Photodgradtion technique offers a good potential to remove color from wastewater. In the present paper these methods were employed for removal of Tornasole RPe and Alizarin yellow G and the techniques were found to be very useful and cost effective for a better removal of dye and comparison between removal dye by hydrogen peroxide, ferrous sulfate, and silver nano particle in sun light effect. We obtain $100 \%$ of degradation of dyes.
\end{abstract}

Keywords: Photodgradtion Treatment, Silver Nano Particle

\section{Introduction}

Dye represents a major class of synthetic organic pigments that are manufactured worldwide and have a variety of applications such as textiles, paper, foodstuff, and cosmetic. The toxicity and carcinogenic nature of these dyes and their precursors pose a threat to the environment Moreover; their degradation often leads to the formation of highly carcinogenic aromatic amines. For example paminoazobenzene has been classified as a carcinogenic compound and there has been a restriction on the production of dyes based on this molecule (Bouberka, Z. Khenifi, A. Benderdouche, N.Derriche, Z., 2006). However dyes continue to be a source of pollution in industrial processes, which utilize dyes to colour paper, plastics as well as natural and artificial fibers. Wastewaters from dyeing industries are released into nearby land or rivers without any treatment because the conventional treatment methods are not cost effective. In recent years, photo catalytic degradation has attracted increasing attention as cleaner and greener technology for removal of toxic organic and inorganic pollutants in water and wastewater (Lian, L. Guo, L. and Guo, C., 2009). Semiconductor photo catalysis appears to be a promising technology that has a number of applications in environmental system such as air purification, water disinfection, water purification, and hazardous waste remediation. Hydrogen peroxide photochemical degradation of organic pollutants in general, and a dye in particular in wastewater is a favored and promising technique (Mehment, D. Ysemin, O. and Viahir, 2006). The organics are completely mineralized into water and $\mathrm{CO}_{2}$ without generating any harmful byproducts. This technique has been employed for the photomineralisation of large number of dyes such as methylene blue. In the present paper these methods were employed for removal of Tornasole RPe and Alizarin yellow.

And the techniques were found to be very useful and cost effective for a better removal of dye and comparison between removal dyes by hydrogen peroxide, ferries sulfate and silver nano particle.<smiles>O=c1cccc2oc3cc(O)ccc3nc1-2</smiles>

Fig. 1. Structure of Tornasole RPe 
<smiles>O=C(O)c1cc(/N=N/c2ccc([N+](=O)[O-])cc2)ccc1O</smiles>

Fig. 2. Structure of Alizarin yellow $G$

\section{Instrumentation}

All experiments of photo degradation were conducted in a sun light. For photo degradation, $0.05 \mathrm{M}$ solution of Tornasole $\mathrm{RPe}$ and Alizarin yellow $\mathrm{G}$ in $25 \mathrm{~mL}$ of dye solution concentration was added and irradiated with sun light at different time. To ensure efficient mixing of $8 \% \mathrm{H}_{2} \mathrm{O}_{2}, 0.2 \%$ of ferrous sulfate and silver nano particle. All the experiments were carried out at room temperature (30 \pm $\left.0.1^{\circ} \mathrm{C}\right)$.

\section{Preparations}

a- Preparation of a Aqueous Solution of Tornasole RPe and Alizarin yellow $G$.

preparation 18 solutions tack 6 solutions from each dye and add to these solutions $2 \mathrm{ml}\left[\mathrm{H}_{2} \mathrm{O}_{2}\right] 30 \%$, were prepared 25 $\mathrm{mL}$ of distilled water to ensure efficient mixing then take another 6 solutions of each dye and add $2 \mathrm{ml}$ of silver nano particle and steering to30min, and take 6 solutions of each dye and add $2 \mathrm{ml}$ of [ferrous sulfate] $=0.2 \%$ were prepared 25 $\mathrm{mL}$ of distilled water. All the experiments were carried out at room temperature $\left(30 \pm 0.1^{\circ} \mathrm{C}\right)$. All the solution was irradiation in sun light at different time.

\section{b-Preparation of Silver Nano-Particle}

Take $0.17 \mathrm{~g}$ of $\mathrm{AgNO}_{3}$ in $100 \mathrm{ml}$ of distilled water and boiling it then add $0.103 \mathrm{~g}$ of sodium triacetate contain two molecule of water in $10 \mathrm{ml}$ of distilled water add this solution to silver nitrite solution will appear yellow color. It is most popular preparation of $\mathrm{Ag}$ colloids is chemical reduction of silver salts by sodium borohydride or sodium tricitrate. This preparation is simple, but the great care must be exercised to make stable and reproducible colloid2. (P.Lundahl, R.Stokes, E. Smith, R. Martin, D.Graham, 2008) and (S.D Solomon, M.Bahadory, A.V Jeyarajasingam, S.A. Rutkowsky, C. Boritz, 2007).

Mechanism of reaction could be expressed as follows:

$$
\begin{aligned}
4 \mathrm{Ag}^{+}+\mathrm{C}_{6} \mathrm{H}_{5} \mathrm{O}_{7} \mathrm{Na}_{3}+ & 2 \mathrm{H}_{2} \mathrm{O} \rightarrow 4 \mathrm{Ag}^{0}+\mathrm{C}_{6} \mathrm{H}_{5} \mathrm{O}_{7} \mathrm{H}_{3}+3 \mathrm{Na}^{+} \\
& +\mathrm{H}^{+}+\mathrm{O}_{2} \uparrow
\end{aligned}
$$

\section{Results and Discussion}

In view of the existence of several degradation pathways, the photo degradation was studied under the following experimental conditions in order to define the system completely. a Photo degradation of the dye in the presence of $\mathrm{H}_{2} \mathrm{O}_{2}$

b Degradation of the dye in the presence of silver nanoparticle

c Photo degradation of the dye in the presence ferrous sulfate

\subsection{Effect of Time Irradiation for Alizarin Yellow G (AG)}

The degradation of dye is a complicated process affected by many factors. In this work we study effect deferent compounds as hydrogen peroxide, silver nano particle, frees sulfate on photo degradation process. All the results were based on $24 \mathrm{~h}$ of photo degradation. The results and the analysis were shown in Fig.(3-8). The dosage of time of irradiation without the photodecolorization percent of Alizarin yellow $G$ increased significantly with time of irradiation. This was because the more time of irradiation, the more photogene rated electron $(\mathrm{e}-) /$ hole $(\mathrm{h}+\mathrm{vB})$ pairs will be generated show figures.

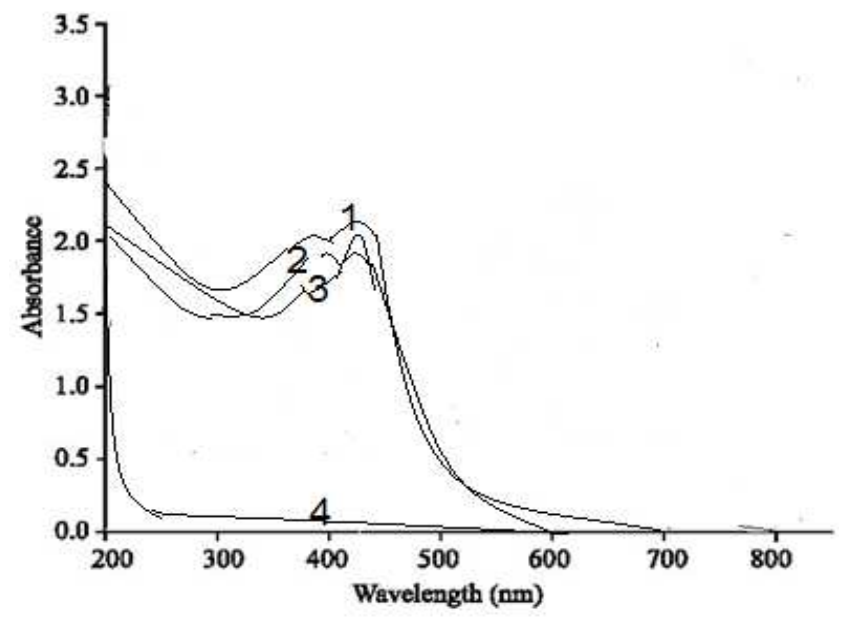

Fig. 3. Effect of time irradiation on degradation of $[A G]=0.05 M$ after irradiation time $60 \mathrm{~min}$. where curve 1 for dye only, curve 2 dye with $\mathrm{H}_{2} \mathrm{O}_{2}$ Curve 3 dye with $\mathrm{FeSO}_{4}$, and curve 4 dye with silver nano particle.

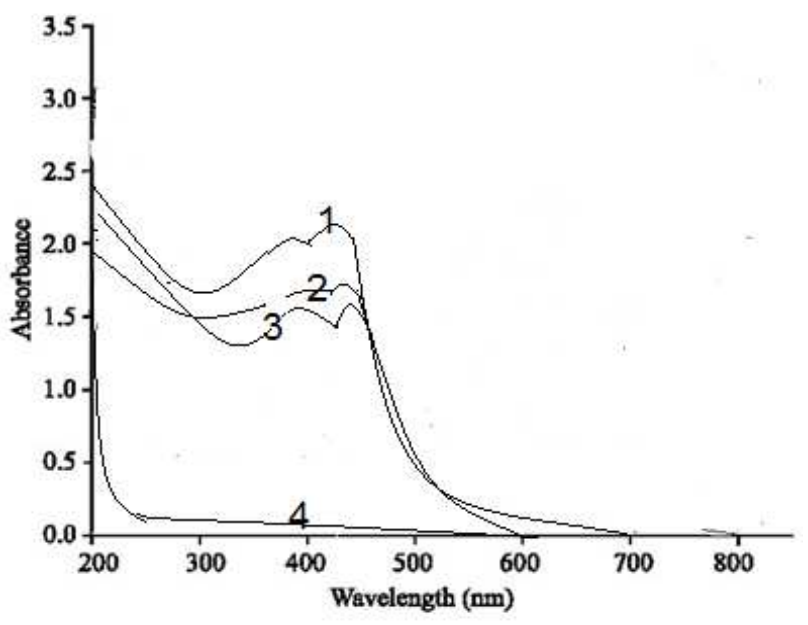

Fig. 4. Effect of time irradiation on degradation of $[A G]=0.05 M$ after irradiation time 120 min. where curve 1 for dye only, curve 2 dye with $\mathrm{H}_{2} \mathrm{O}_{2}$ Curve 3 dye with $\mathrm{FeSO}_{4}$, and curve 4 dye with silver nano particle. 


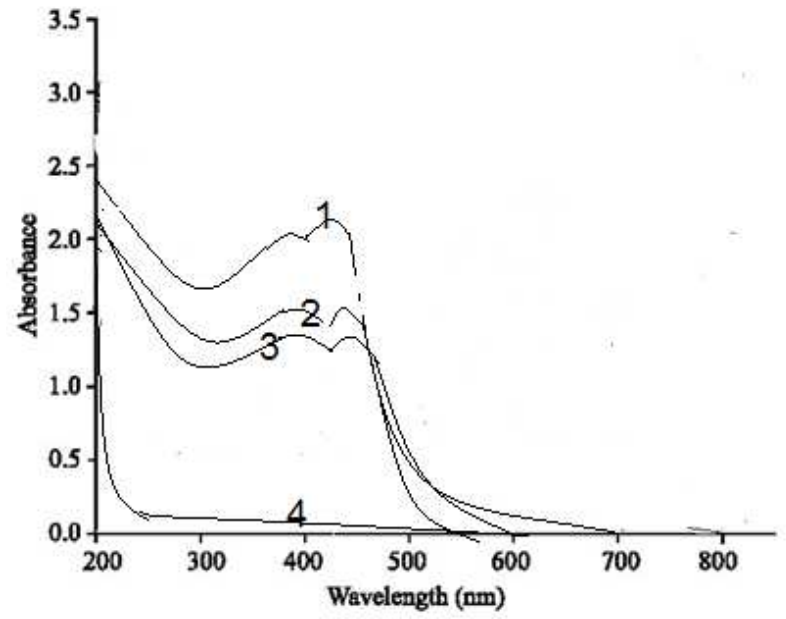

Fig. 5. Effect of time irradiation on degradation of $[A G]=0.05 \mathrm{M}$ after irradiation time 180 min where curve 1 for dye only, curve 2 dye with $\mathrm{H}_{2} \mathrm{O}_{2} 3$ dye with silver nano particle and Curve 4 dye with $\mathrm{FeSO}_{4}$,

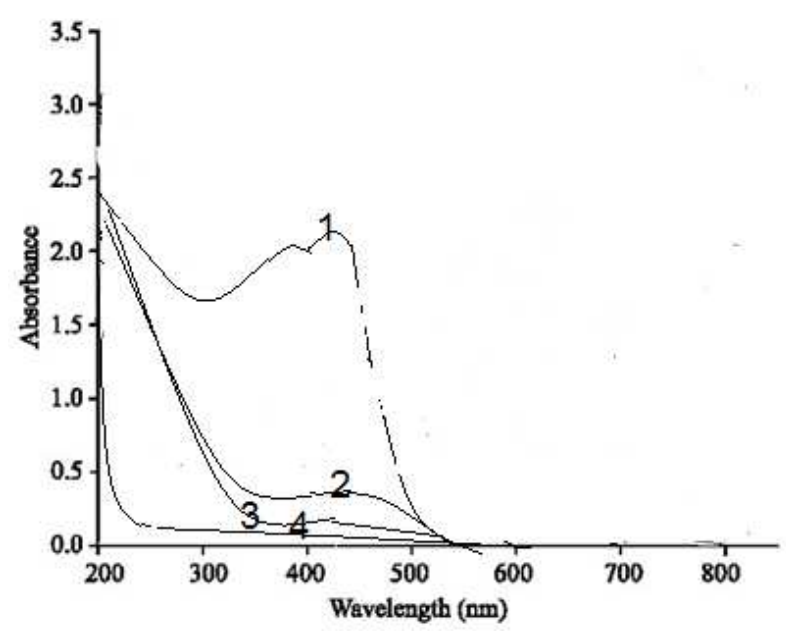

Fig. 6. Effect of time irradiation on degradation of $[A G]=0.05 M$ after irradiation time $24 \mathrm{hr}$. where curve 1 for dye only, curve 2 dye with $\mathrm{H}_{2} \mathrm{O}_{2}$ curve 3 dye with silver nano particle and curve 4 dye with $\mathrm{FeSO}_{4}$,

\subsection{Effect of Time Irradiation for Tornasole(TR)}

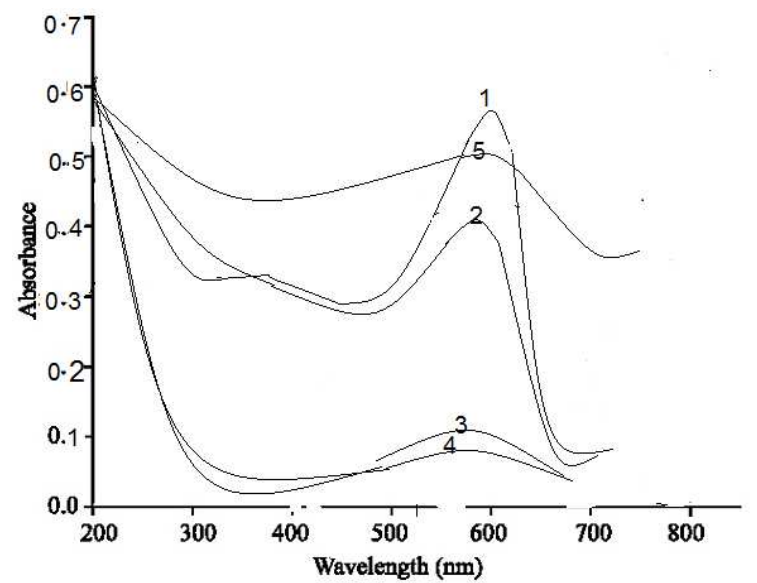

Fig. 7. Effect of time irradiation on degradation of $[T R]=0.05 M$ after irradiation time 15 min where curve 1 for dye only, curve 2 dye with $\mathrm{H}_{2} \mathrm{O}_{2}$ Curve 3 dye with $\mathrm{FeSO}_{4}$, and curve 4 dye with silver nano particle.

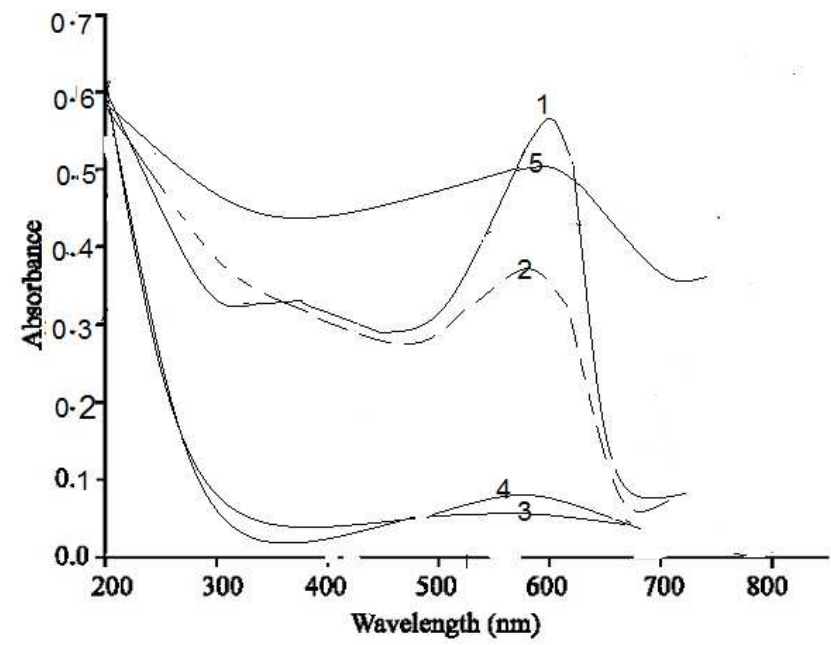

Fig. 8. Effect of time irradiation on degradation of $[T R]=0.05 \mathrm{M}$ after irradiation time 30 min where curve 1 for dye only, curve 2 dye with $\mathrm{H}_{2} \mathrm{O}_{2}$ Curve 3 dye with $\mathrm{FeSO}_{4}$, and curve 4 dye with silver nano particle.

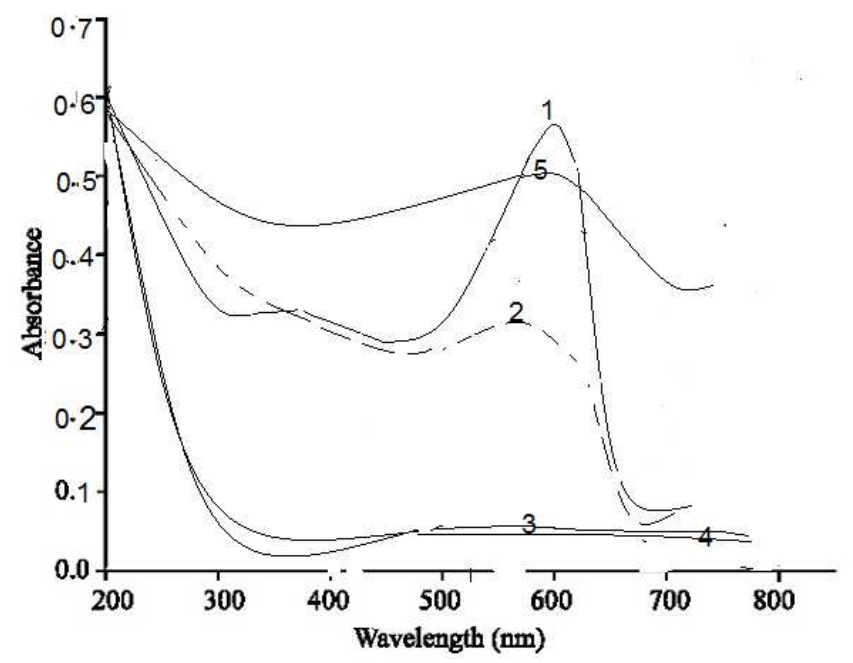

Fig. 9. Effect of time irradiation on degradation of $[T R]=0.05 M$ after irradiation time $45 \mathrm{~min}$ where curve 1 for dye only, curve 2 dye with $\mathrm{H}_{2} \mathrm{O}_{2}$ Curve 3 dye with $\mathrm{FeSO}_{4}$, and curve 4 dye with silver nano particle.

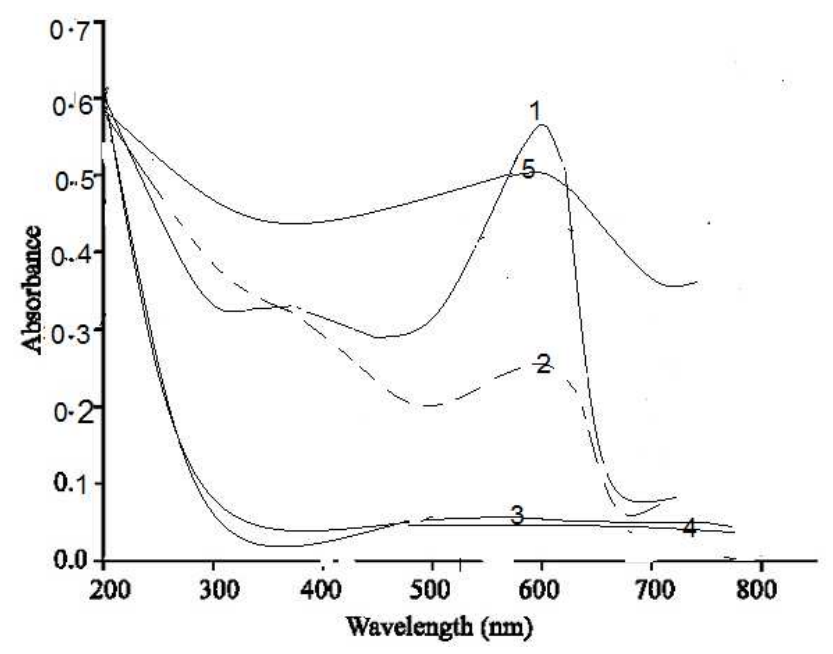

Fig. 10. Effect of time irradiation on degradation of $[T R]=0.05 M$ after irradiation time 60 min where curve 1 for dye only, curve 2 dye with $\mathrm{H}_{2} \mathrm{O}_{2}$ Curve 3 dye with $\mathrm{FeSO}_{4}$, and curve 4 dye with silver nano particle. 


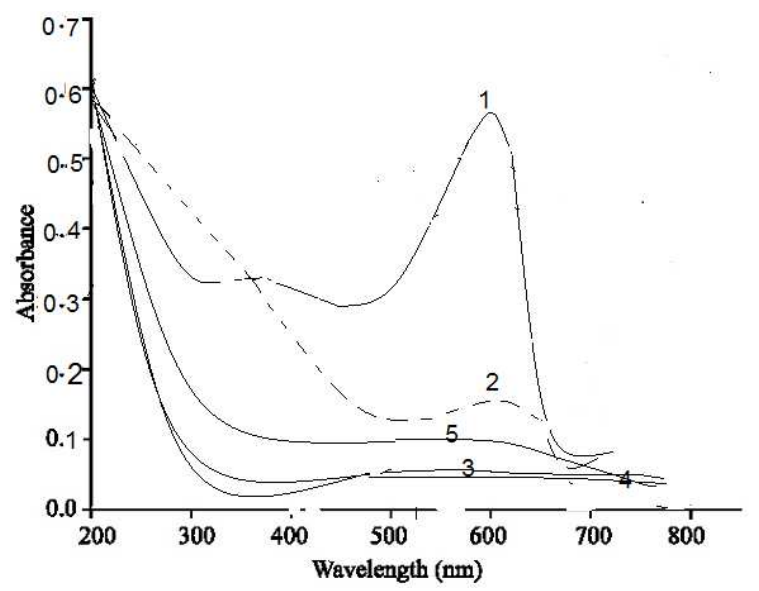

Fig. 11. Effect of time irradiation on degradation of $[T R]=0.05 \mathrm{M}$ after irradiation time 24hr. where curve 1 for dye only, curve 2 dye with $\mathrm{H}_{2} \mathrm{O}_{2}$ Curve 3 dye with $\mathrm{FeSO}_{4}$, and curve 4 dye with silver nano particle.

The degradation of dye is a complicated process affected by many factors. In this work we study effect deferent compounds as hydrogen peroxide, silver nano particle, frees sulfate all the results were based on $24 \mathrm{~h}$ of photo degradation. The results and the analysis were shown in Fig.(9-11) The dosage of time of irradiation without the photodecolorization percent of (TR) increased significantly with time of irradiation. This was because the more time of irradiation, the more photogene rated electron $(\mathrm{e}-)$ /hole $\left(\mathrm{h}+{ }_{\mathrm{VB}}\right)$ pairs will be generated show figures.

\subsection{Effect of Hydrogen Peroxide}

In this work we observed increase time of irradiation with $\mathrm{H}_{2} \mathrm{O}_{2}$ increase photodecolorization percent of $\mathrm{AG}$ and TR significantly with time of irradiation and in high concentration present. This was because increase time of irradiation gives the more photogene rated of $\mathrm{OH}$ radical which discoloration of the dye. The maximum discoloration was about $100 \%$. This is because $\mathrm{H}_{2} \mathrm{O}_{2}$ formed free hydroxyl radical $\left(\mathrm{OH}^{0}\right)$, which make fast degradation of the dye. The detailed mechanism of the dye degradation is the formation of reactive intermediate, which is responsible for the degradation is hydroxyl radical $\left(\mathrm{OH}^{0}\right)$. It is either formed by the decomposition of $\mathrm{H}_{2} \mathrm{O}_{2}$ which is an extremely strong, non-selective oxidant $(\mathrm{E}=+3.06 \mathrm{~V})$ and leads to the partial or complete mineralization of several organic chemicals [Sakthivel, 2003, 65]:

$$
\begin{gathered}
\mathrm{h}^{+}{ }_{\mathrm{VB}}+\mathrm{H}_{2} \mathrm{O}_{2} \rightarrow \mathrm{OH}^{0}+\mathrm{OH}^{0} \\
\mathrm{OH}^{0}+\text { dye } \rightarrow \text { degradation of dye }
\end{gathered}
$$

The percentage of degradation was calculated from the following equation:

$$
\text { Degradation } \%=\left[1-\mathrm{A}_{\mathrm{t}} / \mathrm{A}_{0}\right] \times 100
$$

Where $A_{0}$ initial absorbance and at $A_{t}$ finial absorbance [Rashed et al., 2007, 73].

\subsection{Effect of Ferrous Sulfate}

In this reaction we have two effects on dyes structure:

$1-\mathrm{Fe}^{2+}$ bonded to $\mathrm{N}$ and $\mathrm{O}$ atoms present in the dye structure, adsorption of dyes

2-formation $\mathrm{HO}^{\circ}$ radical leads to formation of a mixture of various aliphatic and aromatic molecules and aliphatic molecules have a lower reactivity toward hydroxyl radicals than aromatic structures [Tuhkanen T. A., Beltrán, F. J., 30 (1995) 1463].

$$
\mathrm{Fe}^{2+}+\mathrm{H}_{2} \mathrm{O}+\mathrm{h}+\mathrm{VB} \rightarrow \mathrm{Fe}^{3+}+\mathrm{HO}^{\bullet}+\mathrm{OH}^{-}
$$

\subsection{Effect of Silver Nano Particle}

In this work we can see that addition of silver nano particle play important roles of dye photo decolonization percent of AG and TR 100\% Colloidal particles are increasingly receiving attention as important starting points for the generation of micro and nanostructures. It comes from small sizes and high surface/volume ratio. Manufacturing entire objects from pure silver metal or coating them with silver is prohibitively expensive for consumer items but research has found that impregnating other materials may be where may be occur adsorption for dye on surface of colloidal particles where this particle act as adsorbent has high surface. Surface Plasmon resonance induced by silver $(\mathrm{Ag})$ nano particles leads to an increase in an absorption coefficient of dye the effect has been theoretically described as an increase of local electromagnetic field nearby metal surfaces which is found when wavelengths of irradiation sources are correlated with the optical absorption of the surface Plasmon resonance. In this study, for a cost-effective process, we prepared the Ag nano particles with sizes in a range of $50-100 \mathrm{~nm}$ using a reduction method show fig. $(12,13)$.

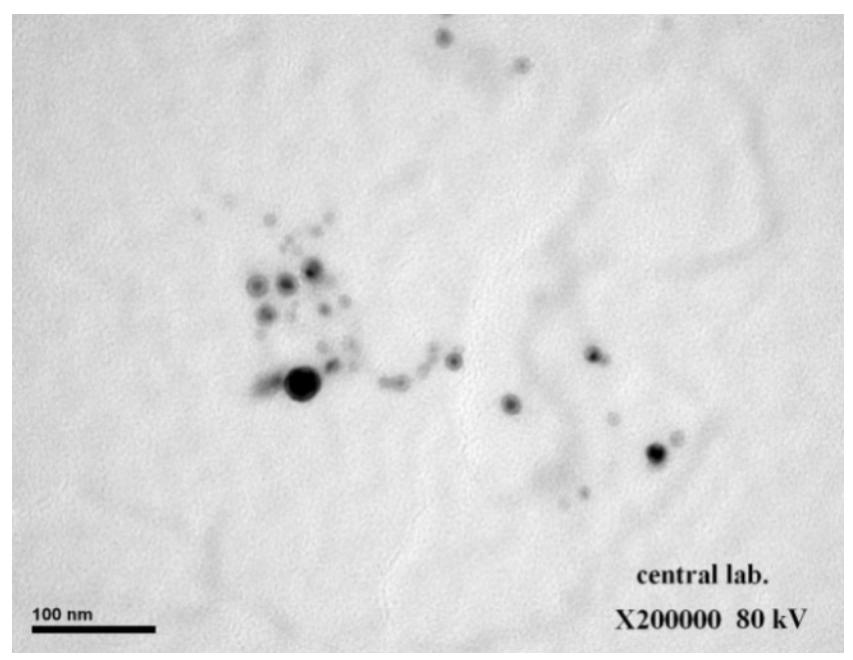

Fig. 12. Showing SEM image of nano-particles produced 


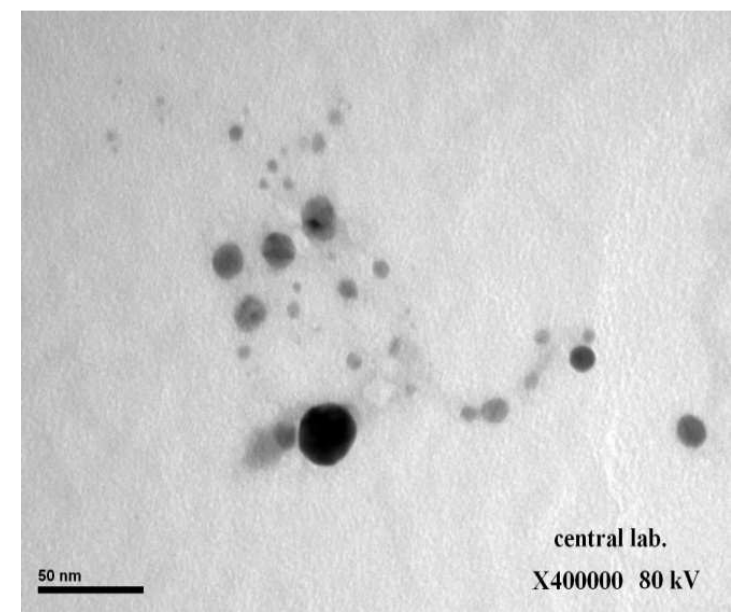

Fig. 13. Showing SEM image of nano-particles produced

\section{Conclusion}

These methods were employed for removal of Tornasole RPe and Alizarin yellow and the techniques were found to be very useful and cost effective for a better removal of dye and comparison between removal dyes by hydrogen peroxide, ferries sulfate and silver nano particles. The results and the analysis show dosage of time of irradiation without the photodecolorization percent of (TR and AG) increased significantly with time of irradiation. The obtained results showed that the decolonization of investigated mordant dyes were feasible to be decolorized by $\mathrm{Fe}^{+2}$ process, silver nano particle and $\mathrm{H}_{2} \mathrm{O}_{2}$. The decolorization efficiency of the investigated dyes by $\mathrm{Fe}^{+2}$ was better than that of the adsorption process for $\mathrm{AG}$ and $\mathrm{TR}$ and $\mathrm{AG}$ completely decolorized in $24 \mathrm{hr}$.

\section{References}

[1] Bouberka, Z. Khenifi, A. Benderdouche, N.Derriche, Z., Removal of Supranol Yellow 4GL by adsorption onto Crintercalatedmontmorillonite, J. Hazard. Mater, 133, 154-161 (2006).

[2] Lian, L. Guo, L. and Guo, C., Adsorption of Congo red from aqueous solutions onto Cabentonite, Journal of Hazardous Materials, 161, 126-131 (2009).

[3] Mehment, D. Ysemin, O. and Viahir, A.,Adsorption kinetics and mechanisum of cationic methyl violet and methylene blue dyes onto sepiolite, Dyes and Pigments, 1, 1-13 (2006).

[4] Lundahl,P. Stokes, R. Smith,E., Martin,R., Graham,D., Micro \& Nano Letters , 3(2) 62-65 (2008).

[5] Rashed, M.N and El-Amin, A.A.Photocatalytic degradation of methyl orange in aqueous $\mathrm{TiO}_{2}$ under different solar irradiation sources J. physical Sciences. 2: 73-81 (2007).

[6] Sakthivel, S., Neppolian B., Shankar B.V. and Palanichamy, M .Solar photocataytic degradation of azo dye: comparison of photocatalyiz efficiency of $\mathrm{ZnO}$ and $\mathrm{TiO}_{2}$ j. sol Ener Mater, Sol. 77:68,(2003).

[7] Solomon, S.D., Bahadory, M., Jeyarajasingam, A.V., Rutkowsky, S.A., Boritz, C., and. Mulfinger,L., Journal of Chemical Education , 84 , 322-325 (2007).

[8] Tuhkanen T. A., Beltrán, F. J., "Intermediates of the oxidation of naphthalene in water with the combination of hydrogen peroxide and UV radiation". Chemosphere. 30 (1995) 1463 